\title{
Brassinosteroid Enhances Resistance to Fusarium Diseases of Barley
}

\author{
Shahin S. Ali, G. B. Sunil Kumar, Mojibur Khan, and Fiona M. Doohan
}

\begin{abstract}
Molecular Plant-Microbe Interactions Laboratory, UCD Earth Institute and UCD School of Biology and Environmental Science, University College Dublin, Dublin 4, Ireland.

Current address of S. S. Ali: United States Department of Agriculture-Agricultural Research Service, Sustainable Perennial Crops Lab, BARC, West Bldg 001, Beltsville, MD 20705.

Current address of G. B. Sunil Kumar: The Biodesign Institute at Arizona State University, Tempe.

Current address of M. Khan: Institute of Advanced Study in Science and Technology, Guwahati-35, India.

Accepted for publication 3 June 2013.
\end{abstract}

\begin{abstract}
Ali, S. S., Sunil Kumar, G. B., Khan, M., and Doohan, F. M. 2013. Brassinosteroid enhances resistance to Fusarium diseases of barley. Phytopathology 103:1260-1267.

Fusarium pathogens are among the most damaging pathogens of cereals. These pathogens have the ability to attack the roots, seedlings, and flowering heads of barley and wheat plants with disease. resulting in yield loss and head blight disease and also resulting in the contamination of grain with mycotoxins harmful to human and animal health. There is increasing evidence that brassinosteroid (BR) hormones play an important role in plant defense against both biotic and abiotic stress agents and this study set out to determine if and how BR might affect Fusarium diseases of barley. Application of the epibrassinolide (epiBL) to heads of 'Lux' barley reduced the severity of Fusarium head blight (FHB) caused

by Fusarium culmorum by $86 \%$ and reduced the FHB-associated loss in grain weight by $33 \%$. Growth of plants in soil amended with epiBL resulted in a 28 and $35 \%$ reduction in Fusarium seedling blight (FSB) symptoms on the Lux and 'Akashinriki' barley, respectively. Microarray analysis was used to determine whether growth in epiBL-amended soil changed the transcriptional profile in stem base tissue during the early stages of FSB development. At 24 and $48 \mathrm{~h}$ post F. culmorum inoculation, there were 146 epiBL-responsive transcripts, the majority being from the 48 -h time point $(n=118)$. Real-time reverse-transcription polymerase chain reaction analysis validated the results for eight transcripts, including five defense genes. The results of gene expression studies show that chromatin remodeling, hormonal signaling, photosynthesis, and pathogenesis-related genes are activated in plants as a result of growth in epiBL.
\end{abstract}

Over the course of evolution, plants have developed complex relationships with microbes, and microbial pathogens have evolved the ability to cause disease on a range of plants. The extent of plant defense responses is influenced by plant hormones. The main plant hormones involved in plant-pathogen interactions are salicylic acid (SA), jasmonic acid (JA), ethylene (ET), and brassinosteroid (BR). The study of BR signaling and its role in disease responses is in its infancy, relative to SA, JA, and ET. BRs and BR signaling have complex positive and negative roles in innate immune responses (49). BR is perceived by the receptor BR-insensitive 1 (BRI1); BRI1 competes with the immune response for the membrane receptor BAK1 (22) but BR can also induce immunity in a BAK1-inependent manner $(1,7)$.

Nakashita et al. (35) were the first to report that BR treatment enhanced biotroph and hemibiotroph resistance. They demonstrated that the BR hormone brassinolide can function in resistance to a broad spectrum of pathogens in tobacco and rice. Although the mechanisms by which BR induced resistance in tobacco and rice are unknown, BR signaling was shown to positively regulate antioxidant systems and metabolites that protect cells from stress (5). BR signaling can induce expression of the gene encoding nicotinamide adenine dinucleotide phosphate

Corresponding author: F. M. Doohan; E-mail address: fiona.doohan@ucd.ie

* The $e$-Xtra logo stands for "electronic extra" and indicates that the online version contains one supplemental figure and two supplemental tables.

http://dx.doi.org/10.1094/PHYTO-05-13-0111-R

(c) 2013 The American Phytopathological Society oxidase to regulate $\mathrm{H}_{2} \mathrm{O}_{2}$ production; the regulation of oxidative stress is a major component of both abiotic and biotic stress tolerance. Active BR signaling can also upregulate nitric oxide production, which promotes abscisic acid (ABA) biosynthesis, resulting in stress tolerance. The transcription factors BZR1 and BES1 play a central role in BR-regulated plant responses to disease. BES1 induces and binds to a key defense regulator, AtMYB30, and together they function cooperatively to promote BR target gene expression (29). BZR1 is a negative regulator of biotic response genes, including $F L S 2$ and SNC1, that are directly involved in defense against pathogens. BR-mediated stress tolerance in Arabidopsis shows interactions with ABA, ET, and SA pathways (17), and BZR1 was shown to directly regulated genes involved in many hormone signaling or biosynthesis pathway (45). BR is implicated in mediating abiotic stress responses through NPR1, a master regulator of SA defense signaling $(17,18)$. However, BR treatment induces pathogenesis-regulated 1 $(P R 1)$ expression in an NPR1-independent manner (17).

In all, $\approx 70 \mathrm{BRs}$ have been isolated from plants (6). Epibrassinolide (epiBL) is a major end product of the BR biosynthesis pathway and is present in almost every plant tissue or organ. It was shown to promote stem elongation and cell division $(20,33)$. The potential of epiBL as a protectant against both biotic and abiotic stress damage has been reported in various agricultural crops $(3,19,48)$. Here, we demonstrate that BR has the potential to protect barley against Fusarium diseases, including the economically devastating Fusarium head blight (FHB) disease, under glasshouse conditions. Using seedling studies, we assessed how epiBL application influences early plant transcriptomic responses to the pathogen Fusarium culmorum. Based on the results, we 
discuss the metabolic changes underpinning BR-mediated control of Fusarium diseases of barley.

\section{MATERIALS AND METHODS}

Plants, fungal, and chemical materials. The two-row barley (Hordeum vulgare) 'Lux' was kindly supplied by Powerseeds, Kildare, Ireland. 'Akashinriki' was kindly provided by K. Sato, Barley Germplasm Centre, Okayama University, Japan. Heads and seedlings of these two genotypes are susceptible to Fusarium fungi (24). F. culmorum is one of the most common species that cause FHB disease (42); the F. culmorum isolates used in this study were strain FCF 200 (kindly supplied by Paul Nicholson, John Innes Centre, Norwich, UK). The fungus was stored at $-70^{\circ} \mathrm{C}$ and, prior to use, were subcultured onto potato dextrose agar (PDA) (Difco, UK) plates and incubated at $25^{\circ} \mathrm{C}$ for 5 days. Fungal conidial inoculum was produced in mung bean broth as described by Brennan et al. (9). epiBL was purchased from Sigma-Aldrich (St. Louis) and a $20-\mathrm{mM}$ stock was prepared in ethanol and subsequently diluted in sterile distilled water to the required concentration.

FHB experiments. All head blight experiments were conducted in a glasshouse, as previously described (24). Barley Lux plants were grown in a heated glasshouse $\left(22^{\circ} \mathrm{C}, 16\right.$-h day, and $12^{\circ} \mathrm{C}, 8$-h night; maximum temperature of $\left.27^{\circ} \mathrm{C}\right)$. At midanthesis, heads (two per plant) were sprayed to runoff with either $20 \mu \mathrm{M}$ epiBL or water (control plants). At $24 \mathrm{~h}$ post hormone application, the same heads were treated with either Tween 20 or F. culmorum conidia $\left(10^{5} \mathrm{ml}^{-1}\right)$, as previously described (24). Visual disease symptoms were recorded at growth stage (GS) 80 (start of dough development) based on the percentage of bleached spikelets per head. Treated heads were harvested at GS 99 (50). The number of seed per head and total seed yield (in grams) per head were recorded. Each treatment combination was applied to 16 plants (two heads per plant) and the experiment was conducted twice (February to April 2012 and March to May 2012) in independent glasshouses in a randomized layout.

Seedling blight experiments. Fusarium seedling blight (FSB) experiments were conducted as described by Khan et al. (25). The plants were grown in a climate-controlled growth room with day and night temperatures of 20 and $12^{\circ} \mathrm{C}$, respectively, with a 12 -h light period $\left(700 \mu \mathrm{mol} \mathrm{m} \mathrm{m}^{-2} \mathrm{~s}^{-1}\right)$ and constant humidity of $85 \%$. Seed of Lux and Akashinriki barley were germinated and grown in a 6-cm-diameter pot containing soil amended with $10 \mathrm{ml}$ of either water or $20 \mu \mathrm{M}$ epiBL, and the stem bases of 10-day-old seedlings were treated with either $0.2 \%$ Tween 20 in $1 \%\left(\mathrm{wt} \mathrm{vol}^{-1}\right)$ agar (Difco Laboratories, Detroit) or conidia $\left(1 \times 10^{6} \mathrm{ml}^{-1}\right)$ of $F$. culmorum. The stem base samples were harvested at 15 days post fungal treatment. Seedling blight stem base disease symptoms were scored as product of lesion length (in centimeters) by lesion color (lesion color scale: 0 , no disease; 1 , very slight brown necrosis; 2 , slight to moderate brown necrosis; 3 , extensive brown necrosis; and 4, extensive black necrosis) (36). This experiment was conducted thrice, and each time it included three replicate pots (each containing two plants) per treatment combination, arranged in a randomized layout. Similar experiments were conducted in order to analyze gene expression via either microarray analysis or reverse-transcription polymerase chain reaction (RTPCR) in Akashinriki. For microarray analysis, three replica experiments were conducted, each including two treatments (treatment 1 involved growth in epiBL-amended soil and stem inoculation with F. culmorum while treatment 2 involved growth in water-amended soil and stem inoculation with $F$. culmorum). Three experiments conducted for RT-PCR studies involved four treatments (growth in soil amended with water or epiBL and stem treatment with either Tween20 and agar or F. culmorum and agar). In all gene expression experiments, samples were harvested at either 24 or $48 \mathrm{~h}$ post stem base treatment, flash frozen in liquid nitrogen, and stored at $-70^{\circ} \mathrm{C}$ prior to RNA extraction, and each experiment included six replicate pots (each containing two plants) per treatment combination.

In vitro plate assay. PDA was amended with epiBL $(0,0.2,2$, $10,20,50,100$, or $200 \mu \mathrm{M})$. Plates were inoculated with a 5-mmdiameter plug of F. culmorum, which was harvested from a 7-dayold PDA plate. Plates were incubated at $25^{\circ} \mathrm{C}$ in darkness. After $72 \mathrm{~h}$, the colony diameter (in centimeters) was measured. The experiment was carried out twice, each containing three technical replicates per treatment.

RNA extraction. Total RNA was extracted from the stem base samples using the protocol described by Chang et al. (10), DNase1 treated according to the manufacturer's instructions (Invitrogen Corp., Carlsbad, CA), and resuspended in diethyl pyrocarbonate-treated water. The quantity of RNA in samples was assessed using an Eppendorf Biophotometer (Eppendorf AG, Hamburg, Germany) according to the manufacturer's instructions. RNA quality of samples was assessed by estimating the RNA integrity number, which averaged $>8$, indicating high-quality RNA.

Microarray analysis. Microarray analysis was used to determine the effect of growth in epiBL-amended soil (relative to mock treatment) on the gene expression in F. culmorum-inoculated stem bases of Akashinriki at either 24 or $48 \mathrm{~h}$ post fungal inoculation (i.e., comparison of gene expression in plants treated with fungus versus plants treated with epiBL plus fungus). Microarray production, hybridization, and data analysis were performed following the minimum information about a microarray experiment (MIAME) guidelines for international standardization and quality control of microarray experiments (8). Microarray analysis was conducted using three composite samples per treatment; composite samples were produced by pooling equal amount of the total RNA from the five replicate samples per treatment per experiment per time point. Total RNA $(1 \mu \mathrm{g})$ from each sample was converted to double-stranded cDNA with the Bioarray singleround RNA amplification and labeling kit (Enzo Life Sciences, PA). After second-strand synthesis, the cDNA was purified with the cDNA purification kit (Enzo Life Sciences). The resulting double-stranded DNA was then used to generate multiple copies of biotinylated cRNA by in vitro transcription with the Bioarray Highyield RNA transcript labeling kit (Enzo Life Sciences). The ratio of absorbance at 260/280 $\mathrm{nm}$ and the yield of each of the cRNAs were determined and the quality of these samples was assessed using an Agilent bioanalyzer (Agilent Technologies, Palo Alto, CA). Biotinylated cRNA $(10 \mu \mathrm{g})$ spiked with biob, bioc, biod, and cre (hybridization controls) was hybridized to an Affymetrix barley genome microarray for $16 \mathrm{~h}$ at $45^{\circ} \mathrm{C}$. Following hybridization, all arrays were washed and stained in an Affymetrix Genechip fluidics station. Stained arrays were scanned with an Affymetrix Genechip scanner 3000. Quality checks and data analyses were carried out using Affymetrix Genechip operating software (gcos) and quality reporter. The array data was normalized per chip and per gene. The per-chip normalization was carried out to the median. For per-gene normalization, the expression value obtained for each gene on each of the three "disease-treated" arrays was divided by the mean value obtained for that gene in the three control-treated arrays. Finally, two lists of significant probes (epiBL-responsive at either 24 or $48 \mathrm{~h}$ post fungal treatment) were generated using a student $t$ test with a fold-change threshold of $\geq 2$ and $\leq-2$, with a $P$ value $<0.05$ (the cut-off previously used) (15). Raw data are in the process of being deposited in MiameExpress.

Sequence analysis. For each probe set, annotations of associated genes or gene homologs were obtained directly from the Affymetrix website (https://www.affymetrix.com/analysis/ netaffx/showresults.affx) or by BLASTx analysis against the nonredundant protein database (2) using the National Centre for Biotechnology Information blast resource (www.ncbi.nlm.nih. gov). The cut-off value of $10^{-15}$ was used as a threshold for the 
expectation scores (e values), and only homologies with an e value of less than the threshold were regarded as significant. Whenever the two descriptions disagreed, the BLASTx description was selected. Based on putative protein functions, genes were assigned to different functional categories according to the Munich Information Centre for Protein Sequences (MIPS) Functional Catalogue scheme (release 2.1) (http://mips.helmholtz-muenchen.de/ proj/funcatDB/search_main_frame.html) (32).

Real-time RT-PCR analysis. Real-time RT-PCR was used to analyze the temporal expression of select epiBL-responsive transcripts of relevance to plant defense. RT of total RNA was conducted as described by Ansari et al. (4), except that the primer used was oligo $\mathrm{dT}_{12-18}$ (Invitrogen). RT products were diluted to $200 \mu \mathrm{l}$, and $2.5 \mu \mathrm{l}$ was PCR amplified in a $25-\mu \mathrm{l}$ volume reaction containing $12.5 \mu \mathrm{l}$ of Premix Ex Taq (Perfect Real Time; Takara, Japan) and $100 \mathrm{nM}$ each forward and reverse transcript-specific primers (Table 1). PCR reactions were conducted in a Stratagene Mx3000 real-time PCR machine (Stratagene) and the program consisted of 1 cycle of $95^{\circ} \mathrm{C}$ for $10 \mathrm{~s}, 40$ cycles of $95^{\circ} \mathrm{C}$ for $5 \mathrm{~s}$ and $60^{\circ} \mathrm{C}$ for $30 \mathrm{~s}$, and 1 cycle of $95^{\circ} \mathrm{C}$ for $60 \mathrm{~s}$. Data were analyzed using Stratagene Mx3000 software (Stratagene). The housekeeping gene used for normalization of real-time RT-PCR data was $\alpha$-tubulin (Affymetrix Contig127_s_at); real-time quantification of target gene and of the housekeeping gene was performed in separate reactions. The threshold cycle $(\mathrm{Ct})$ values obtained by real-time RT-PCR were used to calculate the accumulation of target gene (relative mRNA accumulation) relative to $\alpha$-tubulin transcript by the $2^{\wedge-\Delta \Delta \mathrm{Ct}}$ method, where $\Delta \Delta \mathrm{Ct}=(\mathrm{Ct}$ target gene - Ct $\alpha$-tubulin) (31). Results were based on the average obtained for at least two replicate RT-PCR reactions per sample.

Statistical analysis. Real-time RT-PCR data for Contig10686_at, Contig6276_s_at, and Contig2170_at were normally distributed, as determined using the Ryan Joiner test within Minitab (Minitab release 13.32, 2000; Minitab Inc.). All other data sets were nonnormally distributed. All data sets except the percentage of infected spikelets and seed weight per head data of the FHB experiment could not be transformed to fit a normal distribution using the Johnson transformation within Minitab (Minitab release 13.32, 2000; Minitab Inc.). The homogeneity of data sets across replicate experiments was confirmed by two-tailed correlation analysis (non-normal data: Spearman Rank; normal data: Pearson product moment) conducted within the Statistical Package for the Social Sciences (SPSS 11.0; SPSS Inc.) $(r \geq 0.798 ; P=0.01)$. Therefore, data sets from the replicate experiments were pooled for the purposes of further statistical analysis. The significance of treatment effects was analyzed within Statistical Package for the Social Sciences (SPSS 11.0, SPSS Inc.) by either (i) normally distributed data (one-way analysis of variance with post hoc pairwise least significance difference comparisons, $P=0.05$ ), or (ii) non-normally distributed data (the Kruskal-Wallis $\mathrm{H}$ test).

\section{RESULTS}

Application of epiBL reduced the severity of FHB disease of barley. Glasshouse experiments were conducted in order to determine the effect of epiBL on FHB disease of barley (Lux). In the absence of BR, inoculation with the pathogen $F$. culmorum resulted in $31 \%$ of spikelets displaying typical FHB bleaching symptoms by GS $80(P<0.01)$ (Fig. 1A and C). However, when epiBL was applied $24 \mathrm{~h}$ prior to pathogen inoculation, only $4 \%$ of spikelets showed symptoms (Fig. 1C). EpiBL also reduced losses in grain number and weight caused by FHB disease. Plants pretreated with epiBL prior to Fusarium spp. contained an average of 3.6 more grain per head and an increase of $0.21 \mathrm{~g}$ in grain weight per head (Fig. 1D and E) compared with those only treated with the fungus. Thus, epiBL application reduced the FHB-associated loss in grain weight by $33 \%(P<0.01)$. Grains from epiBL + fungus-treated heads were visually similar to those obtained from control plants (non-pathogen treated); in general, they did not display the fungal growth and shrinkage evident in grains treated with pathogen (no epiBL treatment) (Fig. 1B).

Soil amendment with epiBL reduced the severity of FSB disease of barley. Seedling assays were conducted to determine the effect of soil amendment with epiBL on the development of FSB symptoms on F. culmorum-inoculated stem base tissue of Lux and Akashinriki. It resulted in a 28 and $35 \%$ reduction, respectively, in the severity of visual disease symptoms on Lux and Akashinriki relative to the level of disease symptoms observed on F. culmorum-inoculated plants grown in soil without epiBL amendment $(P<0.05$; Fig. 2$)$.

No evidence that epiBL inhibits the growth of Fusarium spp. in vitro. In vitro plate assays were carried out to determine whether there was any direct inhibitory effect of epiBL on fungal growth on PDA. Even at the highest concentration tested $(200 \mu \mathrm{M})$, epiBL did not inhibit the radial growth of the pathogen (Supplemental Figure 1).

Growth in epiBL-amended soil systemically alters the regulation of defense transcripts. Microarray analyses were used to determine the effect of growth in epiBL-amended soil on the transcriptome profile in Fusarium-infected seedling tissue, relative to the transcriptome of Fusarium-treated plants grown in nonamended soil. Two treatments were compared: epiBL + pathogen versus no hormone + pathogen. Microarray analyses indicated that, at 24 and $48 \mathrm{~h}$ post $F$. culmorum inoculation, 146 transcripts were differentially regulated $(\geq 2$ - and $\leq-2$-fold change) in Fusarium-inoculated barley as a result of soil amendment with epiBL (Supplemental Tables 1 and 2). The majority of these were from $48 \mathrm{~h}$, at which time 96 transcripts were upregulated or activated and 22 transcripts were downregulated in stem base tissue of barley plants grown in epiBL-amended soil, compared with the control treatment. At $24 \mathrm{~h}, 16$ were upregulated and 12 transcripts downregulated due to epiBL treatment. Only one

TABLE 1. Affymetrix probes-specific primers used for real time reverse-transcription polymerase chain reaction (RT-PCR) analysis ${ }^{\mathrm{a}}$

\begin{tabular}{|c|c|c|c|}
\hline Affymetrix Probe ID $^{b}$ & Probe annotation $^{\mathrm{c}}$ & Forward primer $\left(5^{\prime}-3^{\prime}\right)$ & Reverse primer $\left(5^{\prime}-3^{\prime}\right)$ \\
\hline Contig5311_at & Caffeic acid O-methyltransferase & GCAGGGGTTAATCTGTGTGG & GCAGGCTCCCAGTAGAAGTG \\
\hline Contig7886_at & Putative jasmonate-induced protein & GACAGAAGCACAATGCTGGA & ATTCTTCTGCACGGCTATGG \\
\hline Contig10686_at & Athogenesis-related group 5 protein & CCAAGGCGTATTCGTATGCT & ATCCAACGACAGCAAGAACC \\
\hline Contig11534_at & Root-specific lectin precursor protein & CAATATGACGTGCAGGTTGC & TTCGTGCAAGACTACGGTTG \\
\hline Contig15164_at & Cytochrome P450 & ATGCCGGATATTCAGCTCAC & GCATGAGCATGAGCAGTAGC \\
\hline Contig6276_s_at & Abscisic acid-induced protein & CAATTGGAAGGCCATGAGAC & CATGAACGGAAGCAAGGATT \\
\hline Contig2170_at & Pathogen-induced protein WIR1A & CGTCCGTGCAGAGCATATAA & TTTTTCTCACGCCCAGACAT \\
\hline Contig639_at & Pathogenesis-related protein 4 & CCAAGCGTGTACATGGTGTC & CCATTCAAGCTTGCTGCATA \\
\hline Contig127_s_at & $\alpha$-Tubulin & GCATGGAGGAGGGAGAGTTC & CCAGGAGGCAGGCTTCTAGT \\
\hline
\end{tabular}


epiBL-responsive transcript encoding a histone H4 (Contig37_at) was common to both time points.

Differentially expressed genes were categorized based on the MIPS functional catalogue (Fig. 3). At $24 \mathrm{~h}$ post F. culmorum inoculation, 6 of the 28 transcripts that were downregulated in response to epiBL treatment were histones associated with cell cycle and DNA processing (Fig. 3A). Other notable results at $24 \mathrm{~h}$ were the epiBL-mediated upregulation of four defense genes

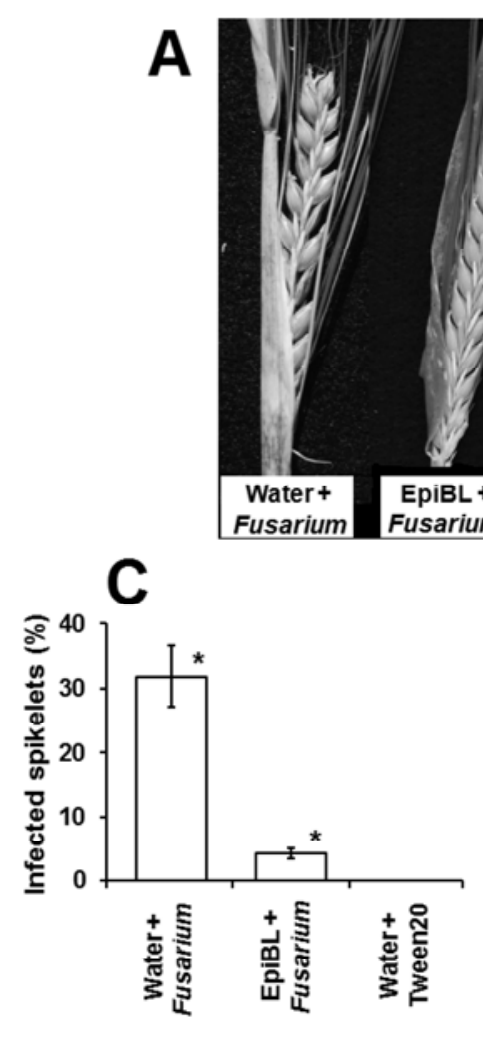

Treatment
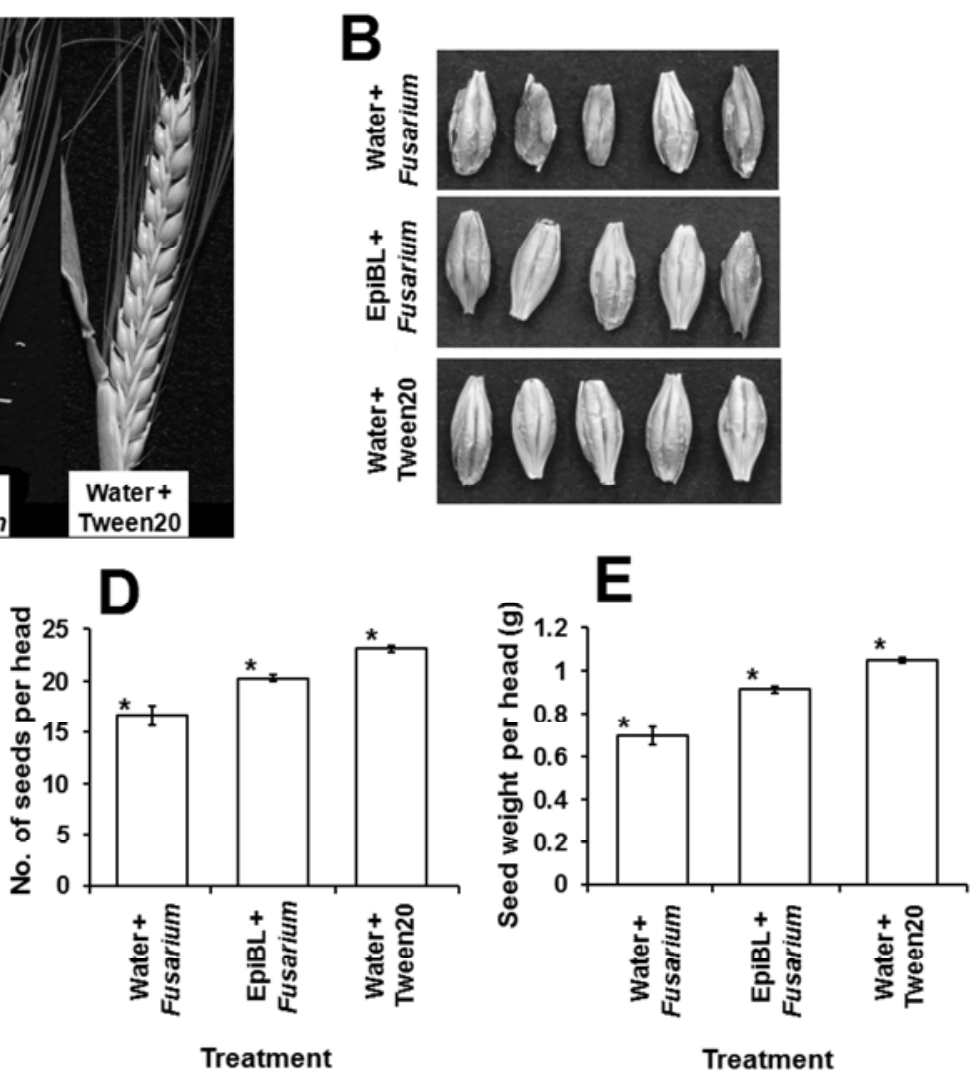

Fig. 1. Effect of exogenous application of epibrassinolide (epiBL) on the symptoms, grain number, and grain weight (per head) in Fusarium head blight (FHB) trials. Plants were treated with either $20 \mu \mathrm{M}$ epiBL or water $24 \mathrm{~h}$ pretreatment with either Fusarium culmorum conidia in Tween 20 solution or Tween20 solution. Disease was assessed at growth stage (GS) 80 and plants were harvested at GS 90 . A, Visualization of the FHB disease symptoms at GS 80. B, Grain quality was visually assessed at GS 90. C, Disease symptoms at GS 80 were quantified as the percentage of infected spikelets per head. At harvest (GS90), the D, number of grains per head and $\mathbf{E}$, weight of the grain in each head were determined. Bar indicates standard error of mean. Values followed by * are significantly different at $P \leq 0.01$.

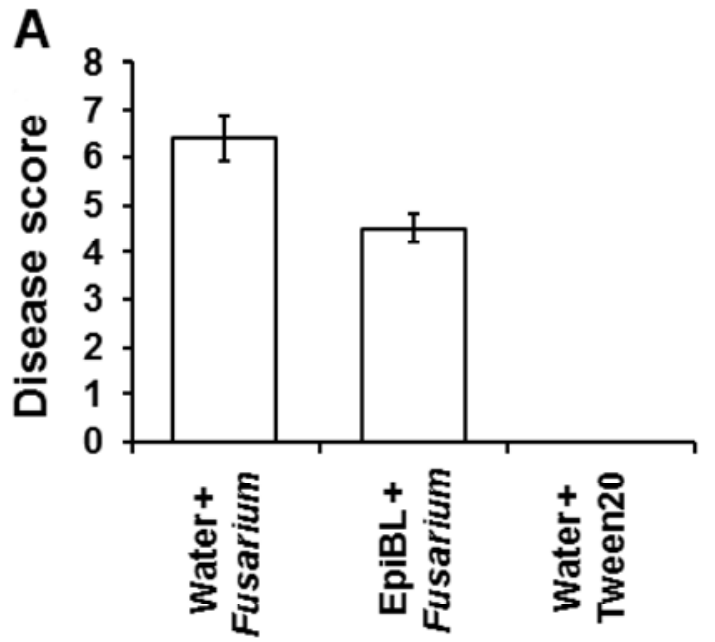

Treatment

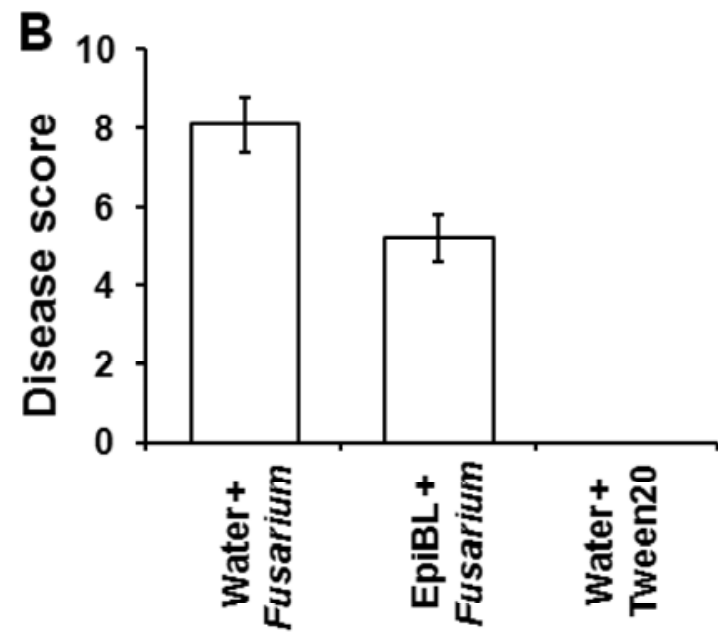

Treatment

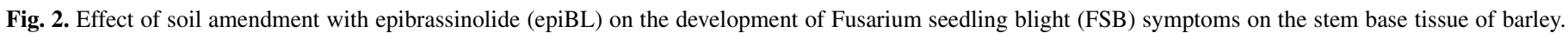

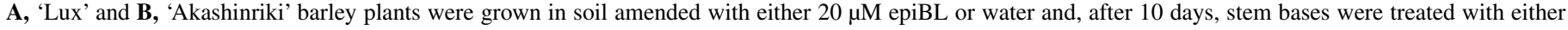

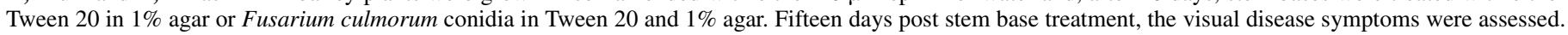

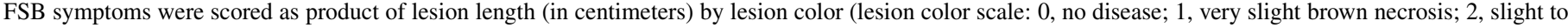

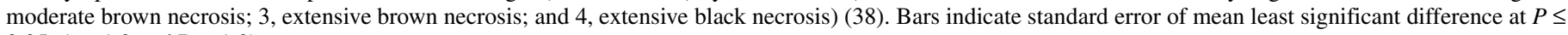
$0.05: \mathrm{A}=1.3$ and $\mathrm{B}=1.9$ ). 
(encoding PR4, WIRIA, asparaginase, and xylanase proteins) and four genes involved in glucan metabolism. Seven epiBL-regulated genes at $24 \mathrm{~h}$ were of unknown function.

By $48 \mathrm{~h}$, there was a dramatic increase in the number of defense genes responsive to epiBL $(n=17)$, with the majority $(n=$ 14) being upregulated due to the hormone treatment of soil. These represented a diverse array of proteins (Fig. 3B), including cytochrome P450s, horcolin, subtilisin, a glutathione-s-transferase, and those responsive to ABA, auxin, and cold. Transcripts encoding a lectin and a jasmonate-inducible protein were downregulated at $48 \mathrm{~h}$ due to epiBL treatment. Among the 14 energyrelated transcripts differentially regulated in response to epiBL, 7 encode photosystem proteins.

Real-time RT-PCR analysis was performed in order to validate the microarray results for eight defense genes (i.e., effect of epiBL on transcription) and to go one step further (i.e., determine the effect of the pathogen on the transcription of these genes). According to microarray analyses, these genes were either upregulated in response to epiBL (Fig. 4A to D), not greatly $(<$ twofold) affected by epiBL (PR-5; Fig. 4E), or downregulated due to epiBL (Fig. 4F to H). In all cases, the RT-PCR results concurred with those of microarray analysis in terms of the effect of epiBL on transcript accumulation. Experiments for RT-PCR included treatment additional to those assessed by microarray analysis; that is, (i) no epiBL, no fungus and (ii) no epiBL, fungus. This enabled us to determine that three of the four epiBL-upregulated genes studied were also upregulated by Fusarium spp.; these were the cytochrome $\mathrm{P} 450$, the pathogenesis protein $\mathrm{PR}-4$, and the pathogen-induced protein WIR1A (Fig. 4A, C, and E; $P<0.05$ ). The effects of both Fusarium spp. and epiBL on the transcription of these genes was additive. The epiBL-upregulated ABA-induced protein 7 gene was not responsive to Fusarium spp. (Fig. 4B). Although the pathogenesis gene PR-5 was responsive to $F u$ sarium spp., RT-PCR concurred with microarray results in that epiBL did not greatly affect the transcription of this gene. RTPCR indicated that caffeic acid O-methyltransferase, root-specific lectin precursor protein, and putative jasmonate-induced protein were all upregulated by Fusarium spp. but, as with microarray, were downregulated by $48 \mathrm{~h}$ post pathogen treatment due to growth in epiBL-amended soil (Fig. 4F, G, and H).

\section{DISCUSSION}

This work demonstrates the potential of epiBL as a control agent for Fusarium diseases of barley. FHB disease is a particularly good target for agents such as epiBL due to the narrow infection window, with the optimal infection time being midanthesis. The glasshouse performance of control agents will undoubtedly be better than field performance. Others have shown that field application of lower concentrations of BR to barley plants (in doses of $\approx 5$ to $15 \mathrm{mg} \mathrm{ha}^{-1}$ ) significantly decreased the extent of leaf diseases induced by mixed fungal infection and increased the crop yield (39). BR also enhanced cucumber resistance to mildew under field conditions. Cucumber seed treatment with epiBL at $0.1 \mathrm{mg} \mathrm{liter}^{-1}$ followed by foliar application at $25 \mathrm{mg} \mathrm{ha}^{-1}$ during flowering stage significantly suppressed mildew (12). Application of BL (in concentrations similar to or higher than used in our study) enhanced resistance of tobacco against Tobacco mosaic virus, Pseudomonas syringae pv. tabaci, and Oidium spp. and of rice against Magnaporthe grisea and Xanthomonas oryzae pv. oryzae (35). Effects of BR on diseases may be concentration dependent, as shown by Nakashita et al. (23). Korableva et al. (26) also showed that the effect of BR on disease can be dependent on the method and time of application, as was the case for late blight of potato, where effects varied from negative to positive. BRs were shown to enhance blight by stimulation of mycelial growth and spore formation by Phytophthora infestans, and retarding wound repair (47). In contrast, BL application after harvesting prolonged dormancy of potato and enhanced resistance to $P$. infestans infection. We found no evidence that BL affected the mycelial growth of $F$. culmorum under the in vitro fungal culture conditions tested herein.

BRs are involved in plant cell elongation, vascular development, senescence, photomorphogenesis, flowering control, and stress responses $(13,27,28)$. Though it is certain that BRs effect the gene expression of various plant growth and development processes, we still do not have sufficient knowledge about their functional mechanisms. Known BR pathway genes were not highlighted within our microarray study but this is not surprising because the experiment was not designed to elucidate the early responses of plants to epiBL. One of the most striking results

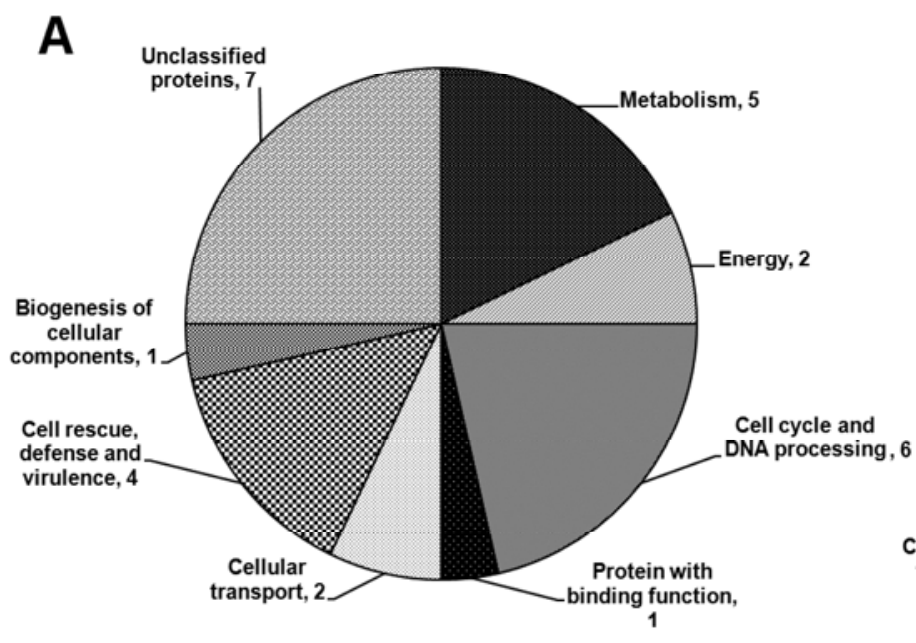

B

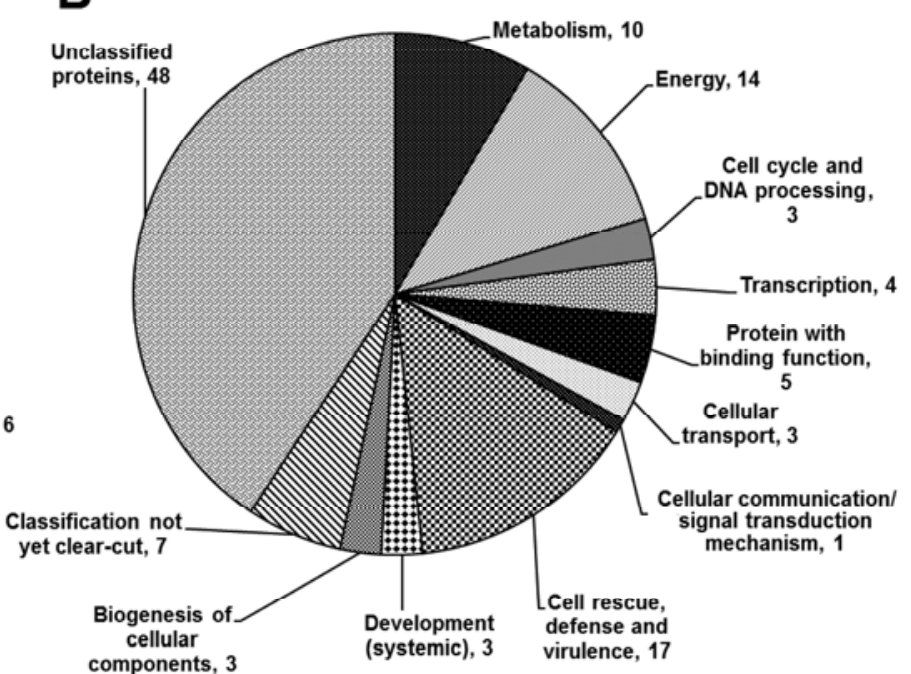

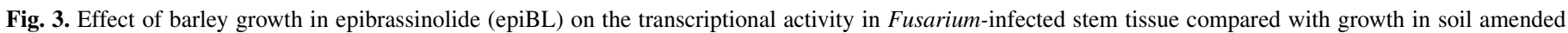

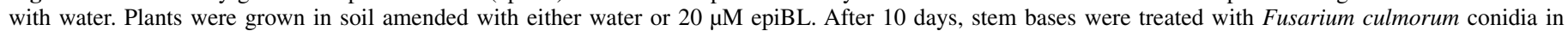

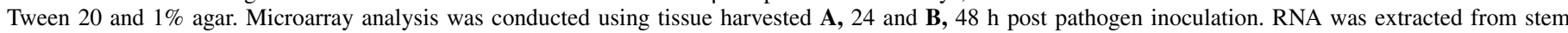

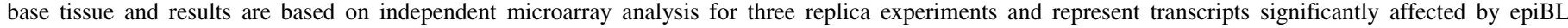

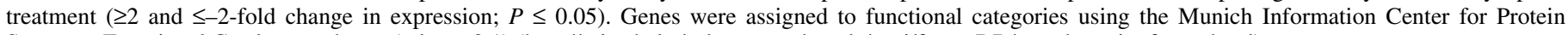
Sequence Functional Catalogue scheme (release 2.1) (http://mips.helmholtz-muenchen.de/proj/funcatDB/search_main_frame.html). 
from the microarray study was the revelation that large numbers of histones were downregulated in Fusarium-inoculated tissue as a result of growth in epiBL-amended soil. Müssig et al. (34) found that, although BR did not significantly alter histone gene expression in wild-type Arabidopsis plants, it inconsistently downregulated His 1-3 is Br-deficient $d w f 1-6$ mutant plants. This suggests that chromatin remodeling is either an effector of or affected by epiBL signaling. This adds further weight to the evidence that BR function requires chromatin remodeling (43). Chromatin remodeling plays an important role in SA-mediated systemic acquired resistance (46) and SA has recently been shown to play a role in FHB resistance (16). Chromatin remodeling could be instrumental for the priming of epiBLresponsive loci to respond to subsequent Fusarium spp. attack.

\section{$24 \mathrm{~h}$ post-stem base treatment}
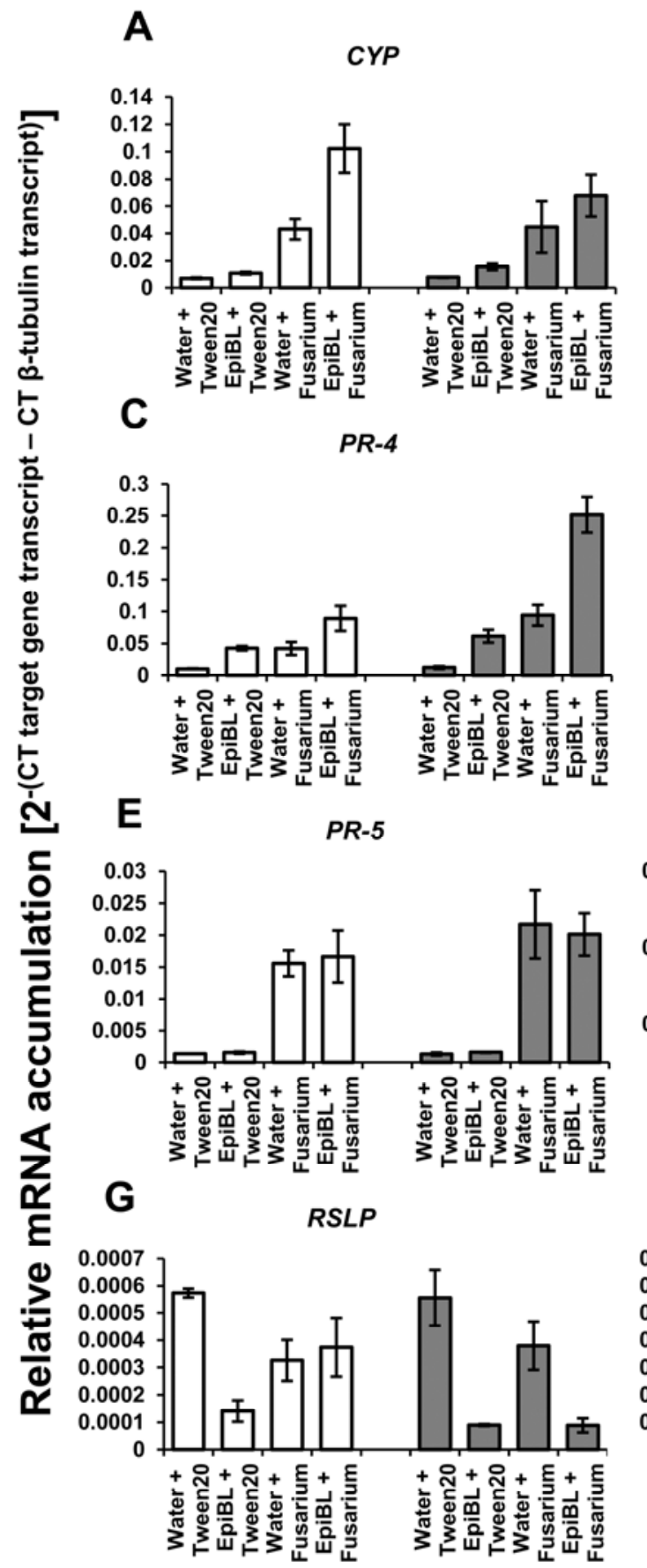

\section{$48 \mathrm{~h}$ post-stem base treatment}

B
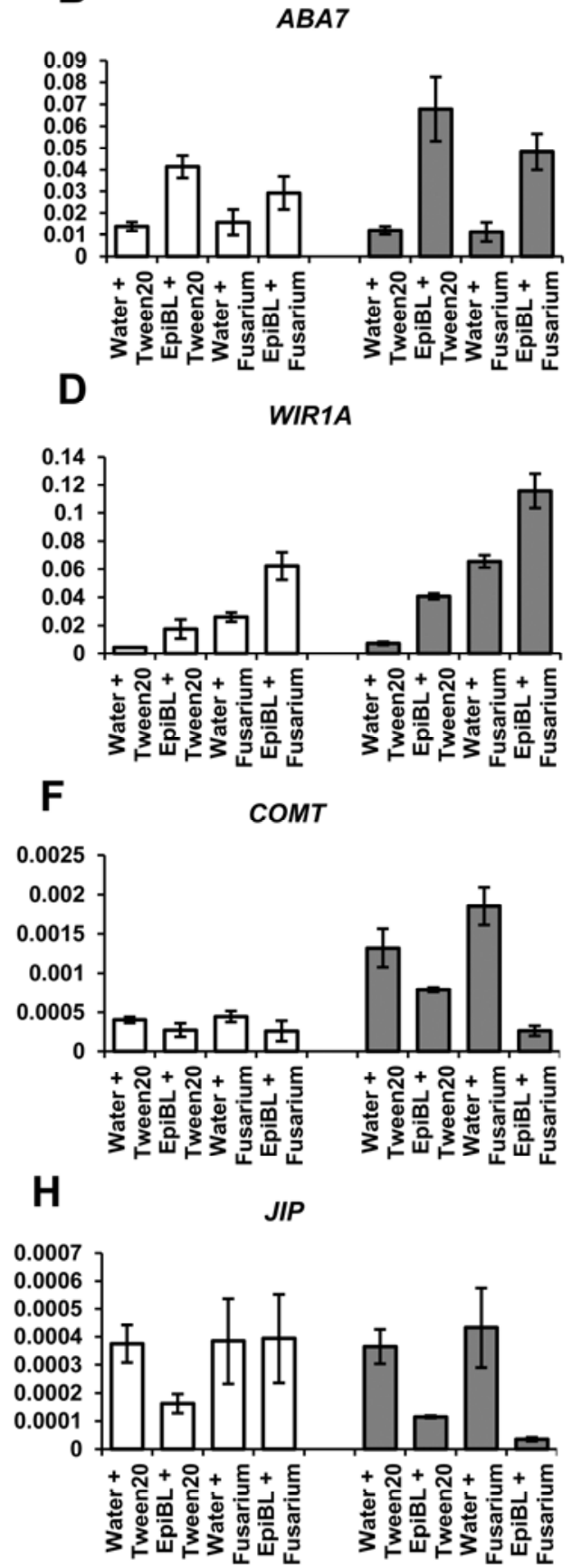

Fig. 4. Effect of epibrassinolide (epiBL) amendment of soil on the expression of specific genes in Fusarium-infected seedlings, as determined by real-time reverse-transcription polymerase chain reaction analysis. Plants were grown in soil amended with either water or $20 \mu \mathrm{M}$ epiBL. After 10 days, stem bases were treated with Fusarium culmorum conidia in Tween 20 and 1\% agar. RNA was extracted from stem bases tissue harvested at either 24 or 48 h post fungal inoculation. Gene accumulations were quantified relative to that of the housekeeping gene $\alpha$-tubulin (Contig127_s_at). Gene represented are A, cytochrome P450 $(C Y P)$ (Contig15164_at); B, abscisic acid (ABA)-induced protein 7 (ABA7) (Contig6276_s_at); C, pathogenesis-related protein 4 (PR-4) (Contig639_at); D, pathogen-induced protein WIRIA (Contig2170_at); E, PR group 5 protein (PR-5) (Contig10686_at); F, caffeic acid O-methyltransferase (COMT) (Contig5311_at); G, root-specific lectin precursor protein $(R S L P)$ (Contig11534_at); and H, putative jasmonate-induced protein (JIP) (Contig7886_at). Genes were identified using Affymetrix barley genome microarray analysis. Results are based on two experiments, each with three replicates per treatment. Bars indicate standard error of mean least significant difference at $P \leq 0.01$ : A $=0.027, \mathrm{~B}=0.018, \mathrm{C}=0.051, \mathrm{D}=0.027, \mathrm{E}=0.014, \mathrm{~F}=0.0001, \mathrm{G}=0.0002$, and $\mathrm{H}=0.0003$ ). 
From the present study, it is clear that BR stimulates select barley defense genes during Fusarium infection. It could be that a subset of these genes are primed by the hormone to respond to the pathogen; however, the microarray analysis conducted herein was not extensive enough to discriminate between hormone-responsive and hormone-primed genes. Nevertheless, it did identify interesting defense genes activated by epiBL. The pathogeninduced protein WIR1A protein is involved in cell wall defense of wheat against rust (14). $\beta-1,3-$ Glucanases were upregulated due to BR treatment in this study, and these have been shown to be antifungal, probably by hydrolyzing their substrates that are structural components in the fungal cell wall (44). Roth et al. (41) also observed that application of BR enhances expression of $\beta$ 1,3-glucanase, chitinase, and peroxidise in potato tubers. In the present study, it was observed that BR induces the transcription of genes encoding subtilisin and a glutathione-S-transferase safener binding protein 1 which may, in turn, trigger the PR proteins $(23,40)$. Our study also demonstrated that BR induces another class of defense proteins called horcolin that can interact with carbohydrates and trigger a stress-signaling pathway $(21,38)$. Upregulation of ABA and auxin-inducible genes and downregulation of a jasmonate-inducible gene indicates a complete alteration of the hormonal profile in barley seedling during Fusarium infection in response to BR treatment. Recent findings have also made it clear that BR signaling components mainly interact with the signaling elements of other hormonal pathways at the transcriptional level (11). Korableva et al. (26) observed that, under the influence of BRs, ET synthesis in tuber tissues increased. Similarly, epiBL treatment may also trigger ET synthesis in barley seedlings, resulting in upregulation of senescenceassociated genes. Thus, our findings further strengthen the concept of crosstalk between BRs and other plant hormones. In a recent study, we observed that indole acetic acid application triggers defense against FHB in barley (37). Another gene worth investigating is steroleosin, which was upregulated in barley seedlings as a result of growth in epiBL during Fusarium infection. Because it is involved in plant signal transduction regulated by various sterols (30), its role in BR-mediated signaling will be interesting to study.

In conclusion, the present study confirmed that BR exerts a wide variety of effects on both plant growth and development in diseased plants, from the activation of plant photosystems to chromatin remodeling. Most importantly, it has shown that BR application in barley triggers systemic signals against the plantpathogenic fungus $F$. culmorum, resulting in a significant reduction in fungal infection and components that contribute to yield loss.

\section{ACKNOWLEDGMENTS}

This work was supported by the Science Foundation Ireland research fund (IN10/IN.1/B3028) and Department of Agriculture Research Stimulus Grant RSF 07 513. S. S. Ali and G. B. Sunil Kumar have equally contributed to the article. We thank K. Sato, Barley Germplasm Centre, Okayama University, Japan for providing Akashinriki seed.

\section{LITERATURE CITED}

1. Albrecht, C., Boutrot, F., Segonzac, C., Schwessinger, B., GimenezIbanez, S., Chinchilla, D., Rathjen, J. P., de Vries, S. C., and Zipfel, C. 2012. Brassinosteroids inhibit pathogen-associated molecular patterntriggered immune signaling independent of the receptor kinase BAK1. Proc. Natl. Acad. Sci. USA 109:303-308.

2. Altschul, S. F., Gish, W., Miller, W., Myers, E. W., and Lipman, D. J. 1990. Basic local alignment search tool. J. Mol. Biol. 215:403-410.

3. Anjum, S. A., Wang, L. C., Farooq, M., Hussain, M., Xue, L. L., and Zou, C. M. 2011. Brassinolide application improves the drought tolerance in maize through modulation of enzymatic antioxidants and leaf gas exchange. J. Agron. Crop. Sci. 197:177-185.

4. Ansari, K. I., Walter, S., Brennan, J. M., Lemmens, M., Kessans, S.,
McGahern, A., Egan, D., and Doohan, F. M. 2007. Retrotransposon and gene activation in wheat in response to mycotoxigenic and non-mycotoxigenic-associated Fusarium stress. Theor. Appl. Genet. 114:927-937.

5. Bajguz, A., and Hayat, S. 2009. Effects of brassinosteroids on the plant responses to environmental stresses. Plant Physiol. Biochem. 47:1-8.

6. Bajguz, A., and Tretyn, A. 2003. The chemical characteristic and distribution of brassinosteroids in plants. Phytochemistry 62:1027-1046.

7. Belkhadir, Y., Jaillais, Y., Epple, P., Balsemão-Pires, E., Dangl, J. L., and Chory, J. 2012. Brassinosteroids modulate the efficiency of plant immune responses to microbe-associated molecular patterns. Proc. Natl. Acad. Sci. USA 109:297-302.

8. Brazma, A., Hingamp, P., Quackenbush, J., Sherlock, G., Spellman, P., Stoeckert, C., Aach, J., Ansorge, W., Ball, C. A., and Causton, H. C. 2001. Minimum information about a microarray experiment (MIAME)-toward standards for microarray data. Nat. Genet. 29:365-372.

9. Brennan, J. M., Egan, D., Cooke, B. M., and Doohan, F. M. 2005. Effect of temperature on head blight of wheat caused by Fusarium culmorum and F. graminearum. Plant Pathol. 54:156-160.

10. Chang, S., Puryear, J., and Cairney, J. 1993. A simple and efficient method for isolating RNA from pine trees. Plant Mol. Biol. Rep. 11:113116.

11. Choudhary, S. P., Yu, J. Q., Yamaguchi-Shinozaki, K., Shinozaki, K., and Tran, L. S. P. 2012. Benefits of brassinosteroid crosstalk. Trends Plant Sci. 17:594-605.

12. Churikova, V. V., Chozhainova, G. N., and Eprintsev, A. T. 1999. The action of epin on the activity of malatdehydrogenase in seedlings of cucumber plants. In: Regulators of Plant Growth and Development, Vol. 5. V. S. Shevelucha, G. I. Karlov, N. P. Karsunkina, E. I. Salnikova, I. V. Skorobogatova, and A. G. Siusheva, eds. Agricultural Academy, Moscow.

13. Clouse, S. D. 1996. Molecular genetic studies confirm the role of brassinosteroids in plant growth and development. Plant J. 10:1-8.

14. Coram, T. E., Huang, X., Zhan, G., Settles, M. L., and Chen, X. 2010. Meta-analysis of transcripts associated with race-specific resistance to stripe rust in wheat demonstrates common induction of blue copperbinding protein, heat-stress transcription factor, pathogen-induced WIR1A protein, and ent-kaurene synthase transcripts. Funct. Integr. Genomics 10:383-392.

15. Coram, T. E., Wang, M., and Chen, X. 2007. Transcriptome analysis of the wheat-Puccinia striiformis f. sp. tritici interaction. Mol. Plant Pathol. 9:157-169.

16. Ding, L., Xu, H., Yi, H., Yang, L., Kong, Z., Zhang, L., Xue, S., Jia, H., and Ma, Z. 2011. Resistance to hemi-biotrophic F. graminearum infection is associated with coordinated and ordered expression of diverse defense signaling pathways. PLoS One 6:e19008.

17. Divi, U., Rahman, T., and Krishna, P. 2010. Brassinosteroid-mediated stress tolerance in Arabidopsis shows interactions with abscisic acid, ethylene and salicylic acid pathways. BMC Plant Biol. 10:151.

18. Dong, X. 2004. NPR1, all things considered. Curr. Opin. Plant Biol. 7:547-552.

19. El-Mashad, A. A. A., and Mohamed, H. I. 2011. Brassinolide alleviates salt stress and increases antioxidant activity of cowpea plants (Vigna sinensis). Protoplasma 249:625-635.

20. Grove, M. D., Spencer, G. F., Rohwedder, W. K., Mandava, N., Worley, J. F., Warthen, J. D., Steffens, G. L., Flippen-Anderson, J. L., and Cook, J. C. 1979. Brassinolide, a plant growth-promoting steroid isolated from Brassica napus pollen. Nature 281:216-217.

21. Grunwald, I., Heinig, I., Thole, H. H., Neumann, D., Kahmann, U., Kloppstech, K., and Gau, A. E. 2007. Purification and characterisation of a jacalin-related, coleoptile specific lectin from Hordeum vulgare. Planta 226:225-234.

22. Jaillais, Y., Belkhadir, Y., Balsemão-Pires, E., Dangl, J. L., and Chory, J. 2011. Extracellular leucine-rich repeats as a platform for receptor/ coreceptor complex formation. Proc. Natl. Acad. Sci. USA 108:85038507.

23. Jordá, L., and Vera, P. 2000. Local and systemic induction of two defenserelated subtilisin-like protease promoters in transgenic Arabidopsis plants. Luciferin induction of PR gene expression. Plant Physiol. 124:1049-1058.

24. Khan, M. R., and Doohan, F. M. 2009. Bacterium-mediated control of Fusarium head blight disease of wheat and barley and associated mycotoxin contamination of grain. Biol. Control 48:42-47.

25. Khan, M. R., Fischer, S., Egan, D., and Doohan, F. M. 2006. Biological control of Fusarium seedling blight disease of wheat and barley. Phytopathology 96:386-394.

26. Korableva, N. P., Platonova, T. A., Dogonadze, M. Z., and Evsunina, A. S. 2002. Brassinolide effect on growth of apical meristems, ethylene production, and abscisic acid content in potato tubers. Biol. Plant. 45:39-43.

27. Krishna, P. 2003. Brassinosteroid-mediated stress responses. J. Plant. Growth. Regul. 22:289-297.

28. Li, J., and Chory, J. 1999. Brassinosteroid actions in plants. J. Exp. Bot. 50:275-282. 
29. Li, L., Yu, X., Thompson, A., Guo, M., Yoshida, S., Asami, T., Chory, J., and Yin, Y. 2009. Arabidopsis MYB30 is a direct target of BES1 and cooperates with BES1 to regulate brassinosteroid-induced gene expression. Plant J. 58:275-286.

30. Lin, L. J., Tai, S. S. K., Peng, C. C., and Tzen, J. T. C. 2002. Steroleosin, a sterol-binding dehydrogenase in seed oil bodies. Plant Physiol. 128:12001211.

31. Livak, K. J., and Schmittgen, T. D. 2001. Analysis of relative gene expression data using real-time quantitative PCR and the 2-[Delta][Delta] CT method. Methods 25:402-408.

32. Mewes, H. W., Albermann, K., Heumann, K., Liebl, S., and Pfeiffer, F. 1997. MIPS: A database for protein sequences, homology data and yeast genome information. Nucleic Acids Res. 25:28-30.

33. Mitchell, J. W., Mandava, N., Worley, J. F., Plimmer, J. R., and Smith, M. V. 1970. Brassins - a new family of plant hormones from rape pollen. Nature 225:1065-1066.

34. Müssig, C., Fischer, S., and Altmann, T. 2002. Brassinosteroid-regulated gene expression. Plant Physiol. 129:1241-1251.

35. Nakashita, H., Yasuda, M., Nitta, T., Asami, T., Fujioka, S., Arai, Y., Sekimata, K., Takatsuto, S., Yamaguchi, I., and Yoshida. S. 2003. Brassinosteroid functions in a broad range of disease resistance in tobacco and rice. Plant J. 33:887-898.

36. Nicholson, P., Simpson, D. R., Weston, G., Rezanoor, H. N., Lees, A. K., Parry, D. W., and Joyce, D. 1998. Detection and quantification of Fusarium culmorum and Fusarium graminearum in cereals using PCR assays. Physiol. Mol. Plant Pathol. 53:17-37.

37. Petti, C., Reiber, K., Ali, S. S., Berney, M., and Doohan, F. M. 2012. Auxin as a player in the biocontrol of Fusarium head blight disease of barley and its potential as a disease control agent. BMC Plant Biol. $12: 224$.

38. Peumans, W. J., and Van Damme, E. J. M. 1995. The role of lectins in plant defence. Histochem. J. 27:253-271.

39. Pshenichnaya, L. A., Khripach, V. A., Volynetz, A. P., Prokkhorchik, R. A., Manzhelesova, N. E., and Morozik, G. V. 1997. Brassinosteroids and resistance of barley plants to leaf diseases. Pages 210-217 in: Problems of Experimental Botany. Byelorussian Science, Minsk, Belarus.

40. Riechers, D. E., Kreuz, K., and Zhang, Q. 2010. Detoxification without intoxication: Herbicide safeners activate plant defense gene expression. Plant Physiol. 153:3-13.

41. Roth, U., Friebe, A., and Schnabl, H. 2000. Resistance induction in plants by a brassinosteroid-containing extract of Lychnis viscaria L. Z. Naturforsch. 55:552-559.

42. Scherm, B., Balmas, V., Spanu, F., Pani, G. Delogu, G., Pasquali, M., and Migheli, Q. 2013. Fusarium culmorum: Causal agent of foot and root rot and head blight on wheat. Mol. Plant Pathol. 14:323-341.

43. Shigeta, T., Yoshimitsu, Y., Nakamura, Y., Okamoto, S., and Matsuo, T. 2011. Does brassinosteroid function require chromatin remodeling? Plant Signal. Behav. 6:1824-1827.

44. Stintzi, A., Heitz, T., Prasad, V., Wiedemann-Merdinoglu, S., Kauffmann, S., Geoffroy, P., Legrand, M., and Fritig, B. 1993. Plant 'pathogenesisrelated' proteins and their role in defense against pathogens. Biochimie 75:687-706

45. Sun, Y., Fan, X. Y., Cao, D. M., Tang, W., He, K., Zhu, J. Y., He, J. X., Bai, M. Y., Zhu, S., and Oh, E. 2010. Integration of brassinosteroid signal transduction with the transcription network for plant growth regulation in Arabidopsis. Dev. Cell 19:765-777.

46. van den Burg, H. A., and Takken, F. L. W. 2009. Does chromatin remodeling mark systemic acquired resistance? Trends Plant Sci. 14:286-294.

47. Vasyukova, N. I., Chalenko, G. I., Kaneva, I. M., Khripach, V. A., and Ozeretskovskaya, O. L. 1994. Brassinosteroids and potato late blight. Prikl. Biokhim. Mikrobiol. 30:464-470.

48. Wang, H. H., Li, K. R., and Hou, H. W. 2005. Research progress of plant stress-resistance promoting related to brassinolides [J]. Agric. Res. Arid Areas 3:046.

49. Wang, Z. Y. 2012. Brassinosteroids modulate plant immunity at multiple levels. Proc. Natl. Acad. Sci. USA 109:7-8.

50. Zadoks, J. C., Chang, T. T., and Konzak, C. F. 1974. A decimal code for the growth stages of cereals. Weed Res. 14:415-421. 